\title{
Homoousia - sprog, krop, trinitet i mediefilosofisk perspektiv
}

\author{
Lektor, dr.theol. \\ Carsten Pallesen
}

\begin{abstract}
From the vantage point of body and language in contemporary philosophy of media the article suggests a reinterpretation of the key term homoousia of the Nicene Creed. The concept of homoousia serves as a guideline for Martin Luther's understanding of the trinity in dialogical rather than narrative terms. The article explores the hermeneutical dimension of body metaphors and language in the Trinitarian faith in a trajectory of reception from Luther to Post-Hegelian theories from Hans-Georg Gadamer to Niklas Luhman, Jean-Luc Nancy and Giorgio Agamben and in contemporary theological interpretations by Carl Andresen, Günter Bader, Eberhard Jüngel and Phillipp Stoellger.
\end{abstract}

Keywords: homoousia - language - body - trinity - hermeneutics philosophy of media

Kroppen betragtes ofte som et underbelyst emne i den teologiske og filosofiske tradition, som nutidige naturalistiske og fænomenologiske teorier vil rette op på. ${ }^{1}$ Kroppen er et urfænomen i lighed med tid og sprog, der umiddelbart "giver sig selv", men ved nærmere eftertanke udgør uløselige vanskeligheder. Vanskeligheden kan udtrykkes med Augustins ord i Bekendelserne om tiden, "når jeg ikke tænker over den, forstår jeg den, når jeg tænker over den, forstår jeg den ikke”. Kroppen er indfanget af tanken og sproget, også når filosofien vil befri kroppens sanselige, før-sproglige aspekter: "lev først, filosofér bagefter", råder Aristoteles, men hvorledes? Dette spørgsmål flytter kropsproblematikken fra de fænomenologiske og naturalistiske måder at spørge på til hermeneutiske, sprog-og mediefilosofiske fremgangsmåder. Navnlig de sidstnævnte blotlægger bibelske og teologiske indsigter i sprogets og kroppens betydning for den trinitariske gudsstanke, som underbelyses i kropsfænomenologiske og materialistiske paradigmer.

I det følgende skal der peges på sprogets betydning for en rehabilitering af kropsfænomenet med udgangspunkt i bibelske og teologiske artikuleringer af kroppen. Sætninger som "Og ordet blev kød" el-

1. Den har været ignoreret i metafysikken, bemærker Heidegger i forbindelse en overvejelse over stemmens og talens fænomen. Den menneskelige legemlighed (stemmen) er ikke noget dyrisk; hvad den er, har metafysikken hidtil end ikke nærmet sig. Anført hos S. Žižek, On Belief(London: Routledge 2000), 55. 
ler "Dette er mit legeme" peger på kroppens teologiske uomgængelighed. Forkyndelsen og bekendelsen kan siges at være indeholdt i disse formler. I det første hovedafsnit opridses den teologihistoriske og bibelske baggrund for krop, sprog og inkarnation. Der aftegner sig her et spændingsfelt mellem en narrativ og en kommunikativ hermeneutisk forståelse af treenigheden. Begge forskyder antikke filosofiske monistiske eller dualistiske paradigmer for forstålsen af de

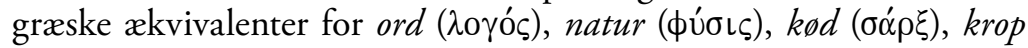

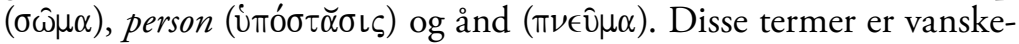
lige at oversætte og præcisere og deres indbyrdes forhold tilsvarende ubestemte. Den mediale og relationelle tænkemåde, som kendetegner de oldkirkelige kristologiske og trinitariske figurer, tilskrives i forskningen påvirkninger fra samtidens græske filosofi. Mulige impulser fra Bibelens hebraiske sprog- og tankesæt, som skal foreslås i det følgende, overvejes sjældent. Et fingerpeg i denne retning giver Heribert Mühlen, der programmatisk har foreslået at tilbageoversætte treenighedslæren til den nytestamentlige korsteologi. ${ }^{2}$ Således bliver den centrale term homoousia i den nikænske bekendelse at forstå som en lære om Guds foranderlighed.

I forlængelse af Mühlens forslag peger denne artikel på muligheden af at forstå homoousien ud fra Bibelens baggrund i den semitiske sprog- og tanke-sfære fremfor dens græske filosofiske kontekster i nyplatonismen. Den semitiske rodfleksion forbliver en dybdedimension i den græske bibeloversættelse (LXX), i nytestamentlig græsk, og følgelig kan forholdet til den hebraiske rodfleksion antages også at spille en rolle for den oldkirkelige trinitariske begrebsdannelse. Her åbnes et udblik til Erich Auerbachs analyse af den kristne sermo humilis, hvor den hebraiske sprogmodel og fortællekunst - ikke på trods af, men i kraft af oversættelserne til græsk og latin - transformerer de græske og latinske stilidealer. ${ }^{3}$

Det andet hovedafsnit udfolder denne tolkning og tilbageoversættelse af homoousien som en hermeneutisk "dekonstruktion" af det antikke filosofiske begreb om substans (ousia). Perspektivet for en moderne mediefilosofi vises med inddragelse af Niklas Luhmanns

2. Heribert Mühlen, Die Veränderlichkeit Gottes als Horizont einer zukünftigen Christologie. Auf dem Wege zu einer Kreuzestheologie in Auseinandersetzung mit der altkirchlichen Christologie (Münster: Aschendorf 1969). Teksten fremhæves af Eberhard Jüngel som en vigtig tilskyndelse bag hans egen hermeneutiske trinitetsteologi, se Eberhard Jüngel, Gott als Geheimnis der Welt (Tübingen: Mohr Siebeck 1982), 1. 3. Erich Auerbach "Sermo Humilis", Literary Language and its Public in Late Latin Antiquity and in the Middle Ages (Princeton: Princeton University Press 1993), 2766. 
analyse af henholdsvis den jødiske og den kristne omgang med skriften og sproget over for den platonske sprogfilosofi.

I det afsluttende afsnit inddrages Luthers salme $\mathrm{Nu}$ fryde sig hver kristen mand som en opsummering af den bibelske og oldkirkelige forstålse af treenigheden som samtalens kommunikative og teologiske virkelighed, som artiklen forsøger at gøre nærværende ud fra moderne mediefilosofi.

\section{Trinitarisk bekendelse mellem fortælling og hermeneutisk samtale}

\section{Nytestamentlige afsat}

Fra liturgien og de nytestamentlige tekster kan springet til kirkefædrenes kristologiske og trinitariske formler synes stort. I de fire evangelier formidles overgangen fra den historiske Jesus til den forkyndte Kristus gennem spillet mellem det, der fortælles om Jesu liv på den ene side og menighedens bekendelse af Jesus som Kristus på den anden. Spillet mellem det kerygmatiske og det narrative ses i den ældste kristne bekendelse, som citeres hos Paulus i 1. Korinterbrev 15, 3-8. Bekendelsen opridser, at Kristus "ifølge Skrifterne" døde for vore synder, at han blev begravet og opstod på tredje dagen, og at han blev set af Kefas og derefter af de tolv og til sidst af Paulus, der betegner sig selv som et "misfoster".

Denne og lignende rudimentære kerygmatiske formler har nutidige narrative forståelser af evangeliet knyttet til ved som modtræk til en angiveligt abstrakt forståelse af kerygmaet hos Bultmann, hvori den historiske og legemlige side af inkarnationen ophæves i "ordet om korset". Kød og krop indikerer her, at ordet er blevet et bestemt menneske. Jesu legemlige opstandelse betegner følgelig identiteten mellem den jordiske Jesus og den herliggjorte Kristus. Fortællingens sammenfletning med kerygmaet er menighedens svar på spørgsmålet om, hvem Jesus var og er. Herved afviser moderne teologer såvel en bastant materialistisk forståelse af kødet, som kendes fra samtidens stoicisme, som en kras dualistisk forståelse af Ordet, det guddommelige Logos. Sidstnævnte kendes fra de samtidige nyplatonske teorier, hvori den legemlige og sproglige formidling reduceres til rene tegn for den sande bagvedliggende verden, gudsrigets virkelighed. Treenighedslæren udgør ifølge den læsning, som her foreslås, en mere differentieret og radikal immanenstænkning, som er mere i pagt med det hebraiske tankesæt end med de metafysiske tankemodeller. 
Den narrative og litteraturkritiske forstålse af den bibelske og teologiske krop er langt hen ad vejen overbevisende. I visse narrative tilgange fører plottets formidling til en harmoniserende udlægning af spillet mellem ordet og kroppen i kristologien og derved til et tab af mening. For at genvinde spændingen i mellem kerygmaet og fortællingen, således som det eksempelvis fremstår i Markuspassionen, er det afgørende at føre fortællingen tilbage til en mere grundlæggende forstålse af sprogligheden som den menneskelige værens særkende. Sproget eller logos forstået som samtale er den mere grundlæggende sproglighed, som Hans-Georg Gadamer finder i den teologiske tradition. ${ }^{4}$ Inkarnationen, "Og ordet blev kød" repræsenterer et vendepunkt i den antikke filosofiske forståelse af hverdagssproget og samtalen. Denne vending er en afgørende impuls for Gadamers filosofiske rehabilitering af hverdagssproget. Stikordsagtigt sagt er sprogets "spekulative midte" og den hermeneutiske erfaring en sekulariseret arv fra den kristne sandhedshændelse. Sandhed som historisk hændelse, der tages op i sprogets midte (Gadamer 1972, 383f), er en ny modalitet af sandhed, der forudsætter kristendommen.

I og med at den græske opfattelse af logikken blev gennemtrængt af den kristne teologi, blev kimen lagt til noget nyt: sproget som det medium, hvori inkarnationsbegivenhedens fulde sandhed formidles. ${ }^{5}$

I antikken tænkes hverdagssproget enkelt sagt som "mening", "fordom", "retorik", uden sandhedsduelighed. I den aristoteliske logik er prædikatsætningen, "der siger noget om noget", den eneste form, under hvilken sproget kan have et forhold til (empirisk) sandhed. Med kristendommen bliver "Logos" menneske eller kød, hvilket betyder, at det præ-eksistente platoniske Logos transformeres til hverdagssprogets jævne tale, der personificeres i Jesus, i Jesu ord og i ordet om Kristus. Logos som logik og begreb bliver herefter udlagt som kommunikationens iboende fornuft, sprogets spekulative midte, der repræsenterer en modalitet af sandheden, som ifølge Gadamer var ukendt for Platon og Aristoteles. For de sidste var logos og sandhed som korrespondens begrundet i uforanderlige ideer og former. De videnskabelige begreber var netop omhyggeligt adskilte fra dagligsprogets dialekter og navnenes flertydighed. Den filosofiske kvalifikation af ideer og former havde matematikken og geometrien som

4. H.-G. Gadamer, Wahrheit und Methode (Tübingen: Mohr Siebeck 1972) 422442.

5. Kursiveret i originalen, citeret fra den danske oversættelse af Gadamer (d.o. Arne Jørgensen), Sandhed og metode (Aarhus: Systime Academic 2004), 404 (Gadamer [1972], 432). 
paradigme for det sande og uforanderlige, mens dialogen og dialektikken, den praktiske fornufts mening og gyldighed, spiller en sekundær rolle. Den vending, som Gadamer fremstiller som sprogets "spekulative midte" kan skematisk udtrykkes som en vending fra $t a-$ len (sætningslogikken, påstanden, prædikationen) som tænkningens logiske grundform til en tænkning, hvor sproget forstået som samtale er tænkningens brudte, endelige, men historisk konkrete medium.

\section{Teologihistoriske forudsatninger}

I den tidlige kristne treenighedstænkning navnlig hos Tertullian fremdrages samtalen som modellen for forståelsen af inkarnationen. I polemik mod gnostiske dualister, der anså kroppen for at være det ondes princip og ånden for den indre og sande verden, der skulle befries fra det ydre og dennesidige, formulerer Tertullian en drastisk kropsretorik. Tertullian bekæmper en filosofisk dualisme, men er ligeså kritisk over for en mytisk, narrativ forstålse af treenigheden. Heller ikke Platons filosofiske dialoger eller de antikke tragedieforfatteres værker er adækvate analogier til den samtale, der udspiller sig mellem personerne i treenigheden. ${ }^{6}$ Ifølge Carl Andresen, som jeg her bygger på (Andresen 1961, 1-39), er Tertullian yderst kritisk over for en platonsk forståelse af kroppen og ånden, også når det gælder forståelsen af treenigheden. Tertullian udlægger de tre personer i treenigheden ud fra skriftsteder i Det Gamle Testamente, hvor tre guddommelige stemmer eller personer taler sammen Første Mosebog 1,26; Jesaja 53, 1; og i Salmernes Bog eksempelvis Salme 2,7; 24,10; 110,1. (Andresen 1961, 22f). ${ }^{7}$ Samtalen i Gud selv er således det eksegetiske forlæg for den guddommelige virkelighed. Udvekslingen og byttet i Gud selv og mellem Gud og det fortabte menneske betyder, at krop og ånd, ord og kød, ikke er statiske begreber, men gensidigt formidlende og udvekslende bestemmelser. Tertullians "prosopografiske" eksegese udartede til "vild eksegese" hos "hæretikerne" og blev afløst af henholdsvis Augustins og de græske fædres mere begrebslige anstrengelser for at gøre rede for treenigheden (Andresen 1961, 38f). Her træder Det Gamle Testamente i baggrunden som eksegetisk belæg, men ikke nødvendigvis som en dyb underliggende impuls, eksempelvis gennem brugen af Salmernes Bog i liturgien. Treenigheden har således ikke oprindeligt ifølge Andresen været forstået som en tilpasning til stoiske og platonske begreber. Sidstnævnte skal snarere ses som

6. Carl Andresen, "Zur Entstehung und Geschichte des trinitarischen Personbegriffes", ZNW 52 (1961), 17.

7. Se hertil med henvisning til Andresen, Günter Bader, Psalterspiel. Skizze einer Theologie des Psalters, HUTh 54 (Tübingen Mohr Siebeck 2009), 384-396 
"overlakeringer" af den struktur i det bibelske ord, som treenigheden læst som samtale artikulerer.

\section{Tilbageoversattelse af Nicanum til den hebraiske sprogmodel}

Det gælder også den ved første blik mest filosofiske af de oldkirkelige bekendelser, den nikænske trosbekendelse fra år 325. Med introduktionen af det fremmedartede og ubibelske begreb homoousia, væsensenhed, bringer de nikænske fædre langvarige stridigheder om forholdet mellem den menneskelige og den guddommelige natur i Kristus og om forholdet mellem de tre personer i treenigheden, Fader Søn og Helligånd, til en afslutning. ${ }^{8}$ Homoousia er den dristige begrebsdannelse, der må udvikles for at kunne udtrykke væsensenheden mellem de forskelle, bevægelser og relationer, som menigheden bekender og erkender som treenighedens indre struktur. Den ubestemte og u-bibelske begrebsdannelse kunne ved nærmere betragtning vise sig at indføre det bibelske ords særegne dynamik i det græske sprogs repræsentative sætningslogik, der her har afløst en tidligere rodflekterende sprogform i den indoeuropæiske sprogudviklings lange perspektiv. Denne metalingvistiske perspektivering bygger på filosoffen og lingvisten Johannes Lohmann, hvis teori Gadamer har fremdraget. ${ }^{9}$

I det hebraiske sprog er meningsdannelsen og tanken ikke formidlet gennem den sproglige og logiske prædikationsmodel, der rendyrkes i den græske filosofi, hvorved sproget her bliver gennemsigtigt for sig selv. Sætningsbygningens elementer fremstår her som statuerne i det græske tempel. Den hebraiske sprogmodel forudsætter heroverfor, at sprogets mindstenhed hverken er sætningen eller ordet, men radikalen, der ikke er et tegn, der repræsenterer, eller et navn for tingen. Radikaler udskærer semantiske felter, som fastlægges nærmere gennem radikalens bøjninger, suffixer og præfixer, hvor den relativt stabile form er de som oftest tre konsonanttegn, som udgør roden (radikalen). Roden er netop ikke et ord, der defineres i en ordbog, men en mellemting mellem ordet og sætningen. Således kan homoousiens ubestemthed og formbarhed ses som en ækvivalent til den semitiske rodfleksion og den dermed sammenhængende forståelse af menneske, sprog og virkelighed. Radikalen er bøjelig og formbar, og således er meningen delvist afhængig af fortolkningen, den hermeneutiske dimension, mens meningen omvendt i den græske sprogmodel er objektiveret. Her bliver mening, tanke og begreb udsondret fra den sproglige artikulering. Prædikationssætningen sikrer her identiteten og entydigheden i det subjekt, hvorom der tales. Denne logik er in-

8. T.F. Torrance, The Trinitarian Faith (Edinburgh: T\&T Clark 1995), 116-145.

9. Johannes Lohmann, "Die Sprache als Fundament des Menschseins", Neue Anthropologie 7/2, red. H.-G. Gadamer, 204-234. 
timt forbundet med den græske filosofis opdagelse af "væren som væren", som lægger grunden for videnskabelig erkendelse, der begrunder erkendelsen i universelle ideer og former, der har frigjort sig fra sprogets mening. Logos er netop ikke sprog, men en indre præeksistent fornuftsstruktur i sjælen, der afspejler kosmos, som lægger afstand til den sproglige flertydighed.

I den semitiske sprogmodel fastlægges meningen ikke i prædikationen, men i udlægningen af den talendes intention og situation. Det semitiske sprog- og tankesæt genererer uendelig fortolkning, som ses i de rabbinske og kristne skriftteologier, som genoptages i den filosofiske hermeneutik, systemteori og dekonstruktion. Disse skoler har præget forskellige alternative tankefigurer, der underløber repræsentationen og derved baner veje for sandhed som fremstilling, præsentation og hændelse.

I det græske og i moderne europæiske sprog er substanskategorien den primære, som de øvrige kategorier ifølge Aristoteles' pros henstruktur føjes til som nærmere bestemmelser af substansen. Heroverfor spalter homoousien det ene, identiteten, i en ubestemmelig relation, hvormed de nikænske fædre med et moderne udtryk kan siges at "dekonstruere" grundbegrebet i den græske metafysik. ${ }^{10}$ Hermed åbner treenighedslæren for samtalen og socialiteten som medium for sandhedshændelse og præsentation, og den foregriber således ifølge Jean-Luc Nancy den labile og selvdekonstruerende sandhedsmodalitet i nutidige teorier om virkeligheden som kommunikation og hændelse. ${ }^{11}$ En vifte af indbyrdes meget forskellige teorier om kommunikation vil i det følgende vil blive inddraget til at udfolde nogle perspektiver af inkarnationen som markør for teologiens rehabilitering af sprogligheden.

Den teologihistoriske baggrund for at stille spørgsmålet om sprog, krop og treenighed udviser en betragtelig spændvidde fra spillet mellem krop, forkyndelse og fortælling over den tidlige treenighedstænknings henvisning til samtalen mellem tre stemmer i visse bibelske tekster som paradigme for udvekslingen mellem Fader, Søn og Ånd til de nikænske fædres kommunikative forståelse af relationer og bevægelser i Gud selv og mellem menneske og Gud. Kroppen opløses i disse formidlinger, men herved forstærkes sprogets og eksistensens kropslige nedfæstelse i treenighedens kommunikative processer. I det følgende fremdrages nutidige filosofiske tilgange, der peger på denne

10. De nikænske fædre kendte antageligt ikke det hebraiske sprog, og de havde store betænkeligheder ved at introducere det nye ord i en så afgørende tekst som Nicænum. Se Torrance (1995), 26.

11. Jean-Luc Nancy, "The Deconstruction of Christianity", Dis-Enclosure. The Deconstruction of Christianity (New York: Fordham University Press 2008), 139-157. 
teologiske arvs impulser for moderne kommunikationsteorier, og som bemærker det, der ifølge Hans-Georg Gadamer og Niklas Luhmann fremstår som nyt i antikken og som impulser for en moderne mediefilosofi. Den teologiske læredannelse foregriber såvel begrebshistorisk og metodisk som indholdsmæssigt Gadamers og Luhmanns egne respektive teorier om hermeneutik og system. ${ }^{12}$

Ud fra moderne sprogfilosofi og hermeneutik belyses kropsfilosofiens optagethed af kroppen som et urfænomen, der enten radikalt unddrager sig sprog og bevidsthed eller mere traditionelt udgør sprogets og bevidsthedens empiriske virkelighedsforankring og den individuelle eksistensfølelses kropslige resonans. De uomgængelige sandhedsmomenter i den kropslige erfaring, som fremdrages i fænomenologien, risikerer imidlertid at udblænde spillet mellem sprog, krop og bevidsthed, dels i den nutidige kropsforståelse, dels i den teologiske forståelse af legemlighed med udgangspunkt i det guddommelige ords eller logos' inkarnation, der netop evokerer en mere kompleks sammenhæng mellem sprog og krop.

\section{Den bibelske krop-omrids}

I den teologiske og bibelske tradition er krop $(\sigma \hat{\omega} \mu \alpha)$ ofte et andet ord for personen. Den hebraiske Bibel er tilbageholdende med brugen af personlige pronominer som "jeg". I stedet omskrives referencen til selvet hyppigt synekdoketisk med kropsdele som arm, fod, knogler, kød, blod, med uorganiske metonymier støv, aske, stok, sten, eller med organer som lever, nyre og hjerte. Kød, blod, knogler og kroppens andre dele kan være tegn for hele personen, eksempelvis i klagesalmen: "Mine dage er borte som røg, mine knogler brænder som en brand" (Sl 102,4). Dermed angives det menneskelige vilkår og ikke kun den sygdomsramte og terminale patients stilling. Den bibelske tanke lægger vægt på fødslens og dødens rammer for livet. Alt ses på baggrund af sprog, tale og ord som den dimension, der i immanensen transcenderer, sætter, skaber og forandrer virkeligheden. Det hebraiske ord for "ord" angives med roden rbd (dabar), der både betyder sag, ting og ord. Således forstået indeholder det bibelske ord en bevægelse og spænding, der forbinder den talendes intentionalitet med sagens objektivitet på en måde, der tendentielt er opløst i de antikke og moderne europæiske sprog. Her har prædikatsætningen siden antikken været modellen for objektivitet og korrespondens mellem ord og virkelighed som filosofisk og videnskabeligt sandhedskriterium, og således er copulaet her det "hængsel", der fikserer repræsentation

12. Begrebet "systema" og hermeneutikkens begreb om "tekst" har ifølge Gadamer deres filosofihistoriske forudsætninger i den oldkirkelige teologi og i antikkens musikteori. Cf. Gadamer (1972), 179, note 5 
og prædikation, og som gør sprogets navne til neutrale entydige prædikater og ord, der kan defineres i ordbogen.

Forstået ud fra den hebraiske sprogrealisme er inkarnationen, Ordet der blev kød, et udtryk for, at den transcendente Gud er blevet menneske. Hvis Gud, menneske ord og kød læses med prædikatsætningens logik bliver udsagnet absurd. I Luhmanns mediefilosofiske reformulering af inkarnationen er Gud i den anden person i treenigheden "gået ind i samfundet". ${ }^{13}$ Dette kan, mener Luhmann, udlægges som religionens tilpasning til alfabetskriftens opfindelse, der forandrer betingelser for den religiøse og al anden kommunikation. Med alfabetskriften afbrydes den mundtlige kommunikation med Gud ansigt til ansigt, som kendes fra arkaiske religioner og folkereligiøsiteten, men ikke fra bogens og skriftens religion.

Den ophøjede strengt stiliserede orale retorik som den, der karakteriserer den religiøse kommunikation i skriftløse kulturer, viger for en genindtræden af det ophøjede i det jævne og hverdagslige. Skriften træder i stedet for templet, og ordet træder i stedet for eller bliver kroppen forstået som stemmens kropslige fænomen, der udfoldes i sangen og liturgiens bærende betydning for bekendelsen.

Herved omvurderes kroppen vis à vis en traditionel dualistisk privilegering af sjælen og ånden over for kroppen og kødet. Også dagligsprogets jævne tale sermo humilis bliver med forkærlighed i evangelierne og hos kirkefædrene ophøjet til medium for Guds virkelighed, og således taler og skriver de kristne et for antikke øren "vulgært" latin for derved at markere inkarnationens betydning (Auerbach 1993, 27-66). Den hebraiske og kristne sermo humilis er kendetegnet ved at bruge den lave prosaiske stil, der omfatter kroppens basale funktioner og behov som medier for det ophøjede. Således kan evangelierne lade et "glas koldt vand" være næstekærlighedens ophøjede udtryk. ${ }^{14}$

Opvurderingen af dagligsproget repræsenterer et brud med den "gode latin", men tillige med Platon og Aristoteles' lære om ideer og former som medier for sandhed og væren, der ikke er underlagt sprogets luner. Selvom Augustin og andre forsøger at kombinere nyplatonismens idélære med en bibelsk forståelse af sprog og virkelighed, lykkes det ikke at undertrykke den implicitte sprog- og kropsfilosofi, som de bibelske traditioner introducerer i hellenismen ikke mindst gennem de bibelske skrifter og oversættelserne af den hebraiske Bibel

13. Niklas Luhmann, "Lässt unsere Gesellschaft Kommunikation mit Gott zu?", Soziologische Aufklärung 4 (Opladen: Westdeutscher Verlag 1987), 230.

14. Auerbach (1992), 36: "A cup of cold water is assuredly a small and worthless thing; but does this mean that the Lord said something small and worthless when he promised that whosoever should give a cup of cold water to the least of his servants would in no wise lose his reward (cf. Matt.10:42)?” 
til græsk og latin. I den efterfølgende latinske skolastiske filosofi spaltes det græske logosbegreb i to ord, som Gadamer bemærker, verbum og ratio, sprog og tænkning, som følge af den kristne inkarnations opvurdering af verbum (Gadamer 1972, 425f).

\section{Estetiske perspektiver i den kristne sprog og kropsforståelse}

Inkarnationen medfører, at den usynlige Gud/Jahve bliver synlig i det dennesidige i en krop, der fødes og dør, og som frigiver det æstetiske og sanselige som medium for det absolutte. Dette ses i kunstens, maleriets og poesiens historie, fra Dante og Rembrandt til Francis Bacon. Her fremstilles bibelske og kristne motiver med en plastisk og undertiden grotesk kødelig realisme. ${ }^{15}$ Den vestlige kunst er således intimt forbundet med teologiens sermo humilis, som det navnlig fremgår af Hegels religionsfilosofi og æstetik.

Et andet kapitel af kroppens teologihistorie er den verdensåbnende rolle, kroppen spiller i den antikke karnevalistiske tradition, komedien, som Det Nye Testamente, og navnlig passionsberetningerne kan siges at tilhøre.

Leib ist das was uns unterläuft [...] Der Leib war Führer in alle Narrheit. Dem kühlen, gelengtlich sogar untererkühlten [...] Geist flößt er Wärme ein; die Bewußtseinsschärfe ruft er in seinen dumpfen Rythmus zurück. Wenn wir zurecht die sublimen Geistestätigkeiten aus dem Affekt der Selbstmacht hervorgehen sehen, dann übt der Leib seine närrische Funktion dadurch aus, daß er die Verschlossenheit des Geistes öffnet. ${ }^{16}$

Kroppen tilhører karnevalismens diskurser, eksempelvis Dantes komedie. ${ }^{17}$ Dante apostroferer kropsudtryk og gestik med en filmisk anskuelighed. Kødets opstandelse og livet efter døden accentuerer den kropslige identitet i gudsforholdet, den kristne sjæl bliver ikke transporteret $\mathrm{i}$ andre legemer (dyr, guder), men den genforenes med

15. Se Gilles Deleuze, "Body, Meat, and Spirit, Becoming-Animal”, Francis Bacon. The Logic of Sensation (London/New York: Continuum 2003), 20-26.

16. Jævnfør G. Bader, Assertio. Drei fortlaufende Lektüren zu Skepsis, Narrheit und Sünde bei Erasmus und Luther, (Tübingen: Mohr Siebeck 1985), 122. Den citerede passage fortsætter, "In der Tat ist der Leib [...] das Substrat der Offenheit, wie er ja nichts als Öffnung in vielerlei Hinsicht ist. Durch jede Pore, durch jede Sinnestätigkeit öffnet sich der Leib, er ist somit reicher als der Geist. Der Affekt, den er verheißt ist Hingabe, Lust, nicht konvulsivische Selbstmacht [...]."For en udlægning heraf se min, "Livet efter døden eller sa(n)gens egen gøren - teologiske randbemærkninger til Nick Caves katalog", Temanummer Ave Nick! Fønix 3-4 (2005), 49-66.

17. Sermo humilis finder ifølge Auerbach sit paradigmatiske litterære nedslag i Dantes Komedie, cf. Auerbach (1993), 66. 
den individuelle jordiske krop, hvilket både er et løfte og en trussel afhængigt af, hvor den afdøde befinder sig i det kosmologiske "renseri” og afstraffelseshierarki. Kroppen er modtagelig for belæring og afretning også i det hinsides.

I et nutidigt mediesociologisk perspektiv kan overvågningskameraer i det offentlige rum og mobiltelefoner forstås som anordninger, der ifølge Giorgio Agamben på linje med sproget og kroppen udfolder den økonomiske treenigheds regimentering af individerne og som nutidige eksempler på det, Michel Foucault kalder "dispositiver". Foucaults dispositiv-begreb fører Agamben tilbage til den latinske oversættelse af det græske navn for den "økonomiske" treenighed "oikonomia". Den tidlige modernitets verdslige dispositiver er en sekular videreudvikling af den kristne pastoralmagt, der har sin model i den økonomiske treenighedslære, og de er særegne "apparater" ved, at de specifikt knyttter sig regulerende og disciplinerende til kroppene. I den tidlige moderne verden blev kroppene ifølge teorien gjort føjelige og disciplinerede gennem indførelsen af en række nye dispositiver som eksempelvis militærdisciplin, sundhed, politi, fængsler og sygehuse, hvori de gale eller syge kroppe blev internerede. Dispositiver er medier, der ikke tvinger, men umærkeligt påvirker vores selvopfattelse og regulerer vores adfærd, og som adskiller den menneskelige krop fra dyret, ${ }^{18}$ og således iagttages udbredelsen af mobiltelefoner som en umærkelig transformation af adfærd og gestik.

\section{Kroppen i fanomenologien}

Men hvad så med filosofien, der traditionelt har undgået kroppen som fejlkilde? Platon og Aristoteles fremhæver fornuftssjælens ikke sanselige participation i og skuen af det uforanderlige. Descartes og Kant hæfter sig ved det tænkende jeg som centrum for den moderne filosofi. Med den sene Edmund Husserl (1859-1838) sker imidlertid noget afgørende nyt. ${ }^{19}$ I sine posthume livsverdensfragmenter bryder kropsfænomenologiens grundlæggende skikkelse Husserl med cogitofilosofien, der fra Descartes til Kant havde stillet subjektet over for verden, livet og kroppen i en repræsentationsmetafysisk model. Med opdagelsen af kroppen som den privilegerede adgang til en fælles verden og andre egoer mener Husserl at have fundet en løsning på omverdensproblemet (Ricœur 2005, 59f). Kroppen danner nemlig ifølge Husserl par med andre kroppe i form af "passive synteser", der gennem slægten, den seksuelle relation, forældre, børn, venskab og

18. Giorgio Agamben, "What is an Apparatus?", i samme What is an Apparatus? and other Essays (Stanford: Stanford University Press 2009), 13, 22.

19. Poul Ricœur, The Course of Recognition (Cambridge, Mass./London: Harvard University Press 2005), 59-61. 
fælleskaber om kulturelle institutioner som bøger og værdier forbinder egoet med alter egoet, og således introducerer solipsismen for en livsverden, der altid allerede er forudsat. Kroppens "passive synteser" er den privilegerede adgang hertil, som cogitofilosofien havde forudsat, men ikke forstået betydningen af. Kroppens passive syntese er i lighed med tiden, den indre tidsbevidsthed, bærende passive ydelser for bevidsthedens aktive synteser, intentionalitetsakter som menen, perciperen, sigen, villen etc. Kropserfaringen afdækkes hos Husserl som en ontologisk forudsætning, der unddrager sig subjektets intentionalitet. Kroppen afdækkes tillige som medium, udtryk, tegn, overgang, kontakt, åbenhed og passage, der muliggør antagelsen af en intersubjektiv livsverden, hvori de oprindeligt monadisk tænkte egoer forbindes med alter egoer. Således er kroppen tænkt som en uomgængelig societær og kommunikativ instans.

Først for en senere sprogfilosofi, som Husserl ikke udfolder, bliver det tydeligt, hvorledes krop og kommunikation spiller sammen, og hvorledes den sproglige formidling er andet og mere end en udvidelse af den kropslige analogi: "pardannelsen" mellem ego og alter. Gennem sprogfilosofi, hermeneutik og systemteori kan det vises, hvorledes den antikke treenighedsteologi kan udfoldes med kropsfænomenologiens intuitioner. Udfordringen er at fastholde differentieringen mellem den kropslige og den sproglige artikulering som gensidigt lukkede og hinanden udelukkende autopoietiske systemer, der ikke desto mindre forudsætter, berører og "irriterer" hinanden. Bevidsthedssystemet kan percipere, men ikke kommunikere, sproget kan kommunikere, men ikke percipere. I det moderne samfund er kunsten og religionen ifølge Luhmann to sociale systemer, der gennem "irritation" og resonans i særlig grad varetager grænsen mellem bevidsthedens perception og de sociale systemers kommunikative virkelighed. ${ }^{20}$

Hvis kristologi og inkarnation kan siges at udgøre kernepunktet i den kristne tro og lære, da er treenigheden en udfoldelse af inkarnationen som kropsligt formidlet fællesskab i Gud selv, der udtrykkes gennem kropslige metaforer for liv, bevægelse, lidelse og død.

Krydsfeltet mellem kropsfænomenologi og teologi kan som antydet skitseres ud fra Agambens redegørelse for antikkens begreb om teologi. Med begrebet "teologi" menes her treenighedslære. Læren om den immanente treenighed kaldes theologia, mens læren om den historiske treenighed kaldes oikonomia (Agamben, 2009, 8f). Kropsog bevægelses-metaforerne i den nikænske bekendelse angiver således den kommunikative dimension, der var ekskluderet fra dominerende

20. Niklas Luhmann, Die Kunst der Gesellschaft (Frankfurt am Main: Suhrkamp 1995), 14-15. 
antikke dualistiske paradigmer, som i de første århundreder fremprovokerede trinitariske og kristologiske stridigheder. Den immanente treenigheds krops- og sprogforståelse i Nicænum udgør således et systemteoretisk modtræk til den magtanalytiske udlægning af den økonomiske treenigheds dispositiver, der i Agamben og Foucaults optik er knyttet til den empiriske krop. I denne læsning nedtones selvreference i den immanente treenighed i en referentiel og repræsentationel historisk og sociologisk analyse af magtens verdslige "apparater", hvori homoousiens mulige innovative potentiale, som Luhmann og Gadamer peger på, nedtones.

Treenighed og kristologi bevæger sig ifølge Nicænum i kropslige skemaer, relationer og prædikater: evig udgåen/ evig udåndet (om Ånden), "evig født", men uskabt, hedder det om Sønnen. Faderen er skaber, men selv uskabt og ufødt "føder". Trinitetens indre relationer er alle kropslige og livsorienterede, men $i k k e$ naturlige biologiske substanser. Faderen "føder", Sønnen er "undfanget af Helligånden" og "født af Jomfru Maria". Disse de-naturaliserede kropsmetaforer kommunikerer transcendensens genindtræden i immanensen, og derved understreges det dennesidige, historien og naturen som dybdedimensionen i kristendommen. Den klassiske skelnen mellem henholdsvis teologisk og økonomisk treenighed lægger op til to forskellige formidlinger. Den første, der paradigmatisk er formuleret i den nikænske bekendelse, betoner samtidigheden i et lukket system af indre relationer og kan forstås med samtalens og kommunikationens hermeneutiske og systemteoretiske begreber, mens den anden, der paradigmatisk er udtrykt i den apostolske trosbekendelse, indbyder til en narrativ udfoldelse af Faderens, Sønnens og Åndens relationer i en historisk proces.

\section{Kritik af den vestlige treenighedstankning hos Augustin}

Trinitetslæren er - ligesom kroppen - en teologisk forlegenhed, så længe den udelukkende bliver forstået ud fra selvbevidstheden, som det ifølge Robert Jenson har været tilfældet i den vestlige teologi med Augustin som en dominerende skikkelse. ${ }^{21}$ Kritikken går på, at Augustin skulle tænke Gud ud fra mennesket og ikke omvendt. ${ }^{22}$ Augustins betoning af selvbevidsthed, vilje, erindring, frihed og synd er ganske vist en uvurderlig filosofisk og teologisk arv, hvis betydning

21. R.W. Jenson: Den treenige Identitet (København: Anis 2008), $161 \mathrm{ff}, 176$.

22. De seneste årtiers Augustinforskning har imødegået denne kritik, se for eksempel Matthew Drever "The Self before God? Rethinking Augustine's Trinitarian thought", HTR 100 (2007), 233-242, og min "Krop og treenighed - Om Guds væsen”, Kroppens Teologi-Teologiens Krop, red. K.B. Nielsen/J.S. Teglbjærg (København: Anis 2011), 211-213. 
ikke skal forklejnes. Problemet er blot ifølge kritikken, at hele pointen med gudslæren går tabt, når treenigheden forstås ud fra psykologiske analogier eksempelvis vilje, erkendelse, erindring. Ifølge kritikken ved Augustin groft sagt hverken, hvad han skal stille op med kroppen eller den trinitetslære, som var udviklet og fastslået som dogme hos de nikænske fædre i Øst (Athanasius, Gregor af Nyssa og andre).

Rådvildheden om treenighedslærens mening og nødvendighed har imidlertid også kendetegnet protestantismen fra sin begyndelse hos Philip Melanchthon frem til Friedrich Schleiermacher. Augustins analogier kan således ses som et symptom på denne forlegenhed, der har afskærmet teologien fra med Heribert Mühlen og nutidige treenighedsteologer som Eberhard Jüngel at tænke treenigheden som en begrebsliggørelse af Guds foranderlighed (Mühlen 1969, 205ff). De nutidige teologiske opbrud og kriser kan ifølge Mühlen åbne blikket for de kriser og opbrud, der lå bag den oldkirkelige græske dogmedannelse, og ses som en chance for en nyfortolkning. Det drejer sig for Mühlen ikke blot om en terminologisk oversættelse af begreber som homoousi, men om en mere differentieret hermeneutisk helhedsforståelse af de oldkirkelige udsagn.

Her kan det være oplysende at indkredse, hvorledes treenighedstænkningen er kommet i stand; hvilket spørgsmål den historisk og systematisk har skullet svare på. På den baggrund vil det være muligt at give nogle fingerpeg om, hvorvidt en moderne kropsfilosofi kan hjælpe teologien i dens forlegenhed, eller om både legemlighed og treenighed snarere må gentænkes ud fra en mere kommunikativ forståelse af begge, som treenighedslæren selv kan tænkes at lægge op til i en moderne reformulering, som det indikeres hos Gadamer og Luhmann.

\section{Fra ousia til homoousia}

Treenighedslæren finder sin afgørende skikkelse hos de græske kirkefædre og er her et forsøg på at tænke Guds enhed som et fællesskab af "handlingscentre", der som homoousiens "svævende" midte bevæger sig mellem substans (ousia) og subjektivitet. Hermed omskrives begreber som person, selv og selvbevidsthed for at undgå at overføre et augustinsk og moderne begreb om subjektivitet på gudslæren. Forholdet mellem disse "centre" i den bibelske Gud formuleres i et opgør med dualistiske forestillinger og begreber. De nikænske fædre yder et modtræk til en tænkning, der tager afsæt i Guds enhed som relationsløs substans, eller til en monisme, der ikke anerkender den anden 
person i treenigheden som sand Gud. Denne tænkning bliver til i debatter med diverse kætterier som modalisme og subordinationisme (Origenes og Arius).

På den baggrund kan det angives, hvorledes den teologiske lære ved at "tilbageoversættes" til den bibelske tale om ord, person og krop kunne genoptages ud fra nutidige mediefilosofiske perspektiver.

Bibelens implicitte hermeneutiske tankemodeller har som sagt at gøre med træk ved det semitiske sprog, som viser sig i mødet med den indoeuropæiske sprogsfære, der finder sted gennem oversættelse fra hebraisk til græsk, og som spiller sammen med teologiske begreber og forestillinger, der udgør et fletværk af oversættelsesmuligheder. ${ }^{23}$ Dette spillerum går imidlertid tendentielt tabt i oversættelsen til græsk og latin. Augustin, der hverken læste græsk eller hebraisk, nødsages til at udvikle sin egen psykologiske teori om treenigheden. I det omfang Augustins gudstanke er fastlagt som en uforanderlig ousia eller substans og ikke som fællesskab eller samtale, bliver personbegrebet tilsvarende fastlagt og ikke åbent og ubestemt, som det indikeres med homoousien. En moderne hermeneutisk og eksegetisk læsning af teksterne kan frigøre forståelsen fra den platoniserende præmis, som gør tanken om Guds foranderlighed umulig at tænke for Augustin, og som volder ham hovedbrud, når han skal gøre rede for, hvorledes Gud, den evige, skaber verden på seks dage og således tvinger til at forbinde det evige med det tidslige. Moderne teologer har andre muligheder for at gentænke det antikke "møde" mellem jødisk og græsk tænkning, som kan anses for at være konstituerende for den europæi-

23. I hovedværket Philosophie und Sprachwissenschaft fremstiller Johs. Lohmann sin teori om sproget i en omfattende sprogvidenskabelig kontekst. Forholdet mellem henholdsvis rod-fleksionens semitiske og stamme- og ord-fleksionens indoeuropæiske sprogmønstre fremgår af artiklen, "Die Sprache als Fundament des Menschseins" i Neue Anthropologie 7/2, red. Hans-Georg Gadamer/Paul Vogler (Stuttgart: Thieme 1975), 204-234. Lohmann er optaget af de to modellers indbyrdes samspil og indvirkning på den europæiske åndshistorie. Et vigtigt eksempel på denne virkningshistoriske bevidsthed er de arabiske og jødiske Aristoteles-receptioner, som blev forarbejdet i skolastikken. Skolastikken indeholder vigtige motiver for gentænkningen af væren, selvbevidsthed, erkendelse, handlen og intentionalitet, som sker i nytidens tænkning hos Descartes, Kant, Hegel, Husserl og Heidegger. Lohmann efterlyser imidlertid en afklaring af sproglighedens særlige betydning for denne filosofihistoriske proces. Det arabiske begreb som skolastikerne gengiver med intentionalitet er knyttet til den semitiske sprogmodels iboende intentionalitet, dens bogstavbevidsthed. Ved begyndelsen til den moderne fænomenologi hos Franz Brentano skilles "intentio” fra tekst og sprog, og således lægges grunden for Husserls undersøgelse af bevidsthedens intentionalitet. Et oprindeligt mere komplekst hermeneutisk begreb bliver ensidigt knyttet til en bevidsthedsfilosofisk udlægning, der sætter parentes om sprog, tekst og ord. En sådan adskillelse er ifølge Lohmann ikke mulig i rodflekterende semitiske sprog. 
ske identitet. ${ }^{24}$ Uden at acceptere den karikerede substansmetafysiske præmis om uforanderlighed og evighed, som siden Nietzsche har været polemisk skydeskive for en generel anti-metafysisk grundtendens, kan den teologiske begrebsdannelse udfordre til en kritisk gentilegnelse af substansbegrebet i filosofien. Filosoffen Werner Stegmaier peger således på ousia-begrebets komplicerede virkningshistorie fra Aristoteles til Descartes, Spinoza og Leibniz. ${ }^{25}$ Bag den selvfølgeliggjorte figur afdækkes bevagelsen som et vandmærke i det angiveligt stivnede begreb.

Mens den græske model skematisk sagt er anlagt på en metafysisk teori om virkeligheden, hvor forudsætningen er, at virkeligheden kan erkendes gennem begreber, der afspejler en objektiv uforanderlig virkelighed, så er den semitiske tanke og sprogforstålse bygget op om intentionalitet, situation og udlægning. Det afgørende er her ikke, hvad tingen er i sig selv, men intentionaliteten, hvad den talende vil sige, det gælder også, når talens ophav er Gud.

Derved får sprogligheden, herunder kropslig gestik, en egen tyngde, som den ikke har hos en Platon eller Aristoteles. ${ }^{26}$

Som et aktualiserende udblik på den hebraiske sprogmodels fortsatte betydning peger Agamben i sin læsning af Gilles Deleuze på Spinozas skrift om en jødisk afart af latinen, hvori Spinoza finder betydningsmuligheder, der ikke findes i standard latin. Han fremhæver nogle særlige semitiske verbalformer i de spanske jøders arkaiske "ladino". Dette sprog tillader en blanding af aktiv og passiv i udtryk som "at besøge sig selv" eller "at gå sig selv" (pasearse). Hermed indikeres en mediumsform, hvor kroppen går med selvet og omvendt. Agamben fremdrager dette som en underliggende impuls i Gilles Deleuzes livsfilosofi, som han med stoikeren Epiktet karakteriserer som en verbal "værensgymnastik". ${ }^{27}$

24. Se Paul Ricœur/André LaCoque, Thinking Biblically (Chicago: Chicago University Press 1998 [Penser la Bible (Paris: Seuil 1998]), xviii.

25. Werner Stegmaier, Substanz. Grundbegriff der Metaphysik (Stuttgart-Bad Cannstatt: Friedrich Frommann Verlag 1977), 9-34.

26. Den antikke græske sprogglemsel er ikke først en sofistisk, stoisk eller neoplatonsk udvikling, men skal allerede findes hos Platon. Se Gadamer (1972), 412: "Man muß als Ergebnis formulieren, daß die Entdeckung der Ideen durch Plato das eigene Wesen der Sprache noch gründlicher verdeckt, als es die sophistischen Theoretiker taten, die im Gebrauch und Mißbrauch der Sprache ihre eigene Kunst (techné) entwickelten." Gadamer nævner ganske vist ikke Luthers sprogtænkning, men det er oplagt at forstå Luthers pointering af det ydre ord som et modtræk imod en metafysisk adskillelse af det ydre og det indre, som Luther netop gør gældende med henvisning til inkarnationen, og som er bærende i hans kristologi.

27. Se G. Agamben, "Absolute Immanence", Potentialities (Stanford: Stanford University Press 1999), 234-35. 
Tilsvarende kan den underliggende semitiske forståelse af sprogligheden tænkes at have været afgørende for kristne teologer i oldkirken, selvom disse ikke selv kendte den hebraiske bibel eller tillagde sproget nogen afgørende betydning. Den bibelske tro artikuleres således nærmest på trods i mødet med filosofien, fordi den semitiske rodfleksion bærer på en merbetydning, der unddrager sig en dualistisk begrebstænkning. Om krydsfeltet mellem den jødiske og den græske erindringskultur siger N. Luhmann:

\begin{abstract}
$\mathrm{Zu}$ den Reichtümern der europäischen Tradition gehört es, daß die jüdische Tradition eine rein religiös, in Textform fixierte Realitätsverdoppelung festgehalten und damit partiell auf die christliche Lehre eingewirkt hat, während die griechische Philosophie den ganz anderen Weg einer sprachlich-begrifflichen Abstraktion genommen hat. ${ }^{28}$
\end{abstract}

Rabbinerne holder, skriver Luhmann, fast ved et kommunikativt bindende forhold til teksten, der indebærer, at teksten ikke kan fejle, men til gengæld kræver de stadig fortolkning med fortolkningskonflikter til følge. Traditionen består her i opbevaringen og overdragelsen af kontroverser som metode til udfoldelse af paradoksier. Hos Platon gælder omvendt, at navne kan fejle og har brug for en stadig tilbagebinding til virkeligheden "in der Form der Erinnerung an urbildhafte Ideen. [...] Beide Versionen artikulieren eine Distanz von imaginärer und realer Realität und liefern dafür das Programm je verschieden ausfüllende Semantik." ${ }^{29}$

Et paradigmatisk eksempel på denne dobbelte arv kunne netop som sagt være udviklingen af begrebet om "homoousien" hos de nikænske fædre. Med dette begreb skabes ikke blot en hjælpekonstruktion til at udtrykke det principielt uudsigelige, nemlig forholdet mellem personerne i treenigheden. Der er tillige tale om en dristig forskydning af det filosofiske ousia-begreb som en benævnelse af den bibelske Guds væsen, idet Guds ousia bestemmes som "homoousia". ${ }^{30}$ Med dette kunstord forskyder de nikænske fædre den aristoteliske udlægning af ousia (substansbegrebet). Forstavelsen "homo" rejser tvivl om enheden i den guddommelige "substans" samtidig med, at den over for arianerne netop vil betone enheden mellem treenighedens hypostaser (personer), specielt væsens-enheden mellem Sønnen og Faderen. Konservative "origenister" betoner heroverfor forskellen mellem per-

28. N. Luhmann, Die Religion der Gesellschaft (Frankfurt/M: Suhrkamp 2000), 63-64.

29. Ibid.

30. Se Torrance (1995), 125, samt Christopher Stead, Philosophy in Christian Antiquity (Cambridge: Cambridge University Press 1994), 160-172. 
sonerne ved i stedet at foreslå begrebet "homoiousia" (væsens-lighed). ${ }^{31}$ Disse teologiske diskussioner bidrager ifølge denne tolkning (utilsigtet) til at dekonstruere ousia-begrebet, der hos Aristoteles fastlægges ud fra kategorilæren. Patristikeren Christoffer Stead, der har viet en række monografier til begrebet, siger, at de teologiske begreber med homoousien træder ud i det ubestemmelige. ${ }^{32}$ Hvad homoousien selv betyder, er omstridt, hvilket i sig selv kan være et betydningsfuldt udtryk for den tilsigtede labilitet, der unddrager sig en mere direkte begrebslig eller prædikativ fiksering. Gud benævnes som en væsensenhed $\mathrm{i}$ en flerhed (syn-ousia, communio eller consubstantia). ${ }^{33}$ Hvis allerede ousia-begrebet ${ }^{34}$ således kan siges at være fluktuerende, så er homoousia det imidlertid i endnu højere grad: "Examining the early uses of homoousios, one is struck by the extraordinary flexibility of the term" (Stead 1994, 167). Noget tilsvarende gælder ifølge Luther for alle vigtige teologiske begrebsdannelser til forskel fra filosofiens traditionelle kategorier og sandhedskriterier. ${ }^{35}$

31. Ibid., 161: "The traditional view assumes that the sense of the ousia was fixed by Aristotle's discussion in the Categories in which he distinguished between the individual and the species. As we have explained, this raises a problem; if homoousios is understood as implying 'same individual', the Creed seems to be declaring the Father, Son and Spirit are one Person, not three. But if it implies only 'same species', it gives no sufficient expression of divine unity; it does not seem to differ materially from the view that the Persons are similar in substance (homoiousios), the view held by fourth-century conservatives who objected to the Nicene Creed precisely because it seemed to abolish the personal distinctions."

32. Ibid. 161, 164, 166. Teologien kan herved siges at bidrage til at spalte substansbegrebets enhed, og derved destabiliseres også dualismens homologier mellem tænken og væren, handlen og natur til fordel for en selvreferentiel værensforståelse, der former sig som en mere eller mindre radikal konstruktivisme. Teologien forudsætter ifølge Luhmann et "afkald på metafysisk grundlagssikkerhed" og kan derfor retrospektivt siges at lægge an til en form for differenshermeneutik, der efterfølgende har udviklet sig i andre videnskaber. Jævnfør for eksempel Luhmann, Funktion der Religion (Frankfurt: Suhrkamp 1977) 257-58, samme, "Kontingenz als Eigenwert der Moderne", Beobachtungen der Moderne (Opladen, Westdeutscher Verlag 1992), 111-12.

33. Denne forskydning af ousia/substans-begrebet kan igen som nævnt tænkes at have haft tilbagevirkninger på den aristoteliske substanskategoris transformationer i skolastikkens teorier om Gud og væren, som det eksempelvis fremstilles af Luhmann. Han eftersporer en sammenhæng mellem substanskategoriens opløsning og kontingensbegrebets opvurdering ved overgangen til det moderne samfund. Jævnfør for eksempel Luhmann, "Transformationen der Kontingenz im Sozialsystem der Religion", Luhmann, 182ff.

34. Således rekonstruerer Werner Stegmaier det filosofiske substans begreb som bevagelse, se Stegmaier (1977), 32-34.

35. Den kristologiske grundfigur communicatio idiomatum (egenskabernes udveksling) i Luthers teologi karakteriserer han selv, som en "sky", som teologien, når den forstår sig selv rigtigt, skal bevæge sig $\mathrm{i}$ - in illa nube ambulemus. Teologiens 
Treenighedslæren kan ud fra disse sprogfilosofiske overvejelser betragtes som et forsøg på en systematisering af den implicitte hermeneutik, der ligger i inkarnationen af det uskabte evige ord, som tematiseres i den immanente treenighed. Den bør nemlig i forlængelse af kirkefædrene kunne tages op i et universelt perspektiv, hvor den ikke kun angår kirken og dens bekendelse i mere snæver betydning. Denne lære kan da ses som udtryk for en bevidst omstilling fra en dualistisk korrespondensmetafysik, som ifølge Johs. Lohmann er tæt forbundet med den indoeuropæiske sprogmodels ordstamme-fleksion. Denne model adskiller sig som nævnt strukturelt fra en semitisk rodflekterende sprogmodel. Mens den førstnævnte tænker virkeligheden ud fra uforanderlige ideer, der svarer til ordstammer og ord, da er den sidstnævnte bygget op om radikaler, der skærer virkelighedsområder ud, som disse fremstår for en forudsat intentionalitet, der altid tænker betydningen ud fra situationen og modtageren. Således er den bibelske Jahve identisk med den i sproget forudsatte vilje og intentionalitet, der hos Platon svarer til det upersonlige logos, der ikke er kendetegnet ved intentionalitet eller transcendens. Den således udlagte bibelske og trinitariske gudstanke er kendetegnet ved en indre refleksivitet og bevægelighed. Den står i et ikke tilfældigt forhold til den semitiske rodfleksion, der med bibeloversættelsen (LXX) og den kristne åbenbaring (NT) "falder ind" i hellenismen. ${ }^{36}$ Ved dette møde får den bibelske tanke en ny historie som filosofiens "andet". ${ }^{37}$ Treenighedslæren er således modellen for den type (konstruktivistisk) filosofi, der har selvrefleksionen (ho-

videnskabelige egenart forklarer Luther i en "vidensskabsteoretisk" redegørelse for, hvorfor teologi ikke kan forenes med aristotelisk metafysik, således som "Sorbonneteologerne" gør, når de overalt forudsætter en integration af tro og viden ud fra en "metafysisk grundlagssikkerhed". Luther vil med udgangspunkt i kristologiens og treenighedslærens "tåger" differentiere mellem tro og viden. Således skal teologien give afkald på at levere grundlagssikkerhed, og således kan den anerkende de forskellige videnskabers (musik, matematik, metafysik, teologi) iboende rationalitet, som selvstændige autopoietiske systemer, som Luhmann ville sige. Luther: "Disp. de divinitate et humanitate Christi", WA 39 II, 104. For en udlægning heraf se Stefan Streiff, "Novis linguis loqui": Martin Luthers Disputation über Joh 1, 14 "Verbum caro factum est” aus dem Jahr 1539 (Göttingen : Vandenhoeck \& Ruprecht 1993).

36. Gud falder eller kommer ind i tænkningen. Jævnfør Emmanuel Lévinas' titel: Dieu qui vient à l'idée (Paris: Vrin 1992).

37. Se Ricœur/LaCoque, Thinking Biblically, xviii. Mødet mellem jødisk og græsk tænkning "was the major risk run by the experience of reading that assured the perenniality of the biblical texts." Dette møde er blevet vor kulturs konstitutive

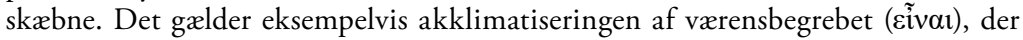
giver det indfødsret i den bibelske og nytestamentlige kontekst, se ibid., 337: "This impressive convergence of Philo, pagan theologians, and especially the Johannine school shows that the choice made by LXX was in harmony with a tradition of translation from Hebrew to Greek that was widespread in the Hellenistic world. This linguistic decision in a way sets a seal on the encounter between two cultures, 
moousien) som grundlag, og som herved adskiller sig fra en dualistisk udlægning af væren og sandhed som korrespondens mellem henholdsvis tenken og veren, handlen og natur (Luhmann 1992, 67).

Ånden er i den forbindelse den person i guddommen, der som tilhører (re)præsenterer forholdet mellem den talende (Faderen) og det talte ord (Sønnen), idet den tredje person (Ånden) evigt udgår fra de to andre som samtalens implicitte analytiker. Denne åndsmodel kompliceres af, at den forbinder sig med det ydre ord i form af inkarnationen og dens tekstlige bevidnelse. Den levende tales samspil med den tilsigtede mening er hverken konstant eller arbitrær, men er en begivenhed, der skal udlægges og genskabes, idet skriften og ordet herved tænkes at have radikal autoritativ og virkelighedskonstituerende betydning. Med inkarnationen tænkes det absolutte derfor som foranderligt og paradoksalt, således som det fastholdes med treenighedslærens begrebsfornyelser. Disse kan tilskrives den "Arrangier- und Montagebewußtsein", der ifølge Luhmann kendetegner den teologiske tænkning, som afløser den metafysiske grundlagssikkerhed som model for sammenhængende tænkning, som kendetegner de hellenistiske korrespondensteorier (Luhmann(1977), 257, note 52). Teologiens temporaliserede bevidsthedsform har en moderne pendant i Gadamers "virkningshistoriske bevidsthed" (Gadamer 1977, 179, note 5).

\section{Luthers kommunikative genfortolkning af homoousien}

Spørgsmålet om forskellen mellem væsens-lighed (homoiousios) og væsens-enhed (homoousios) kan antages at være andet og mere end blot et "akustisk bedrag." ${ }^{88}$ Spørgsmålet går direkte på gudsbegrebets mulighed og gyldighed som et selvreferentielt kommunikativt fællesskab. Når tænkere i den tyske idealisme og særligt Hegel betoner en lignende ikke-substantiel forståelse af ånden som akt, ligger det på linje med oldkirkens teologer og ikke mindst med Luthers forståelse af Guds immanente væsen som samtale eller "trialog". 39

the Hebraic and the Greek, an encounter that, occuring by chance, became a destiny, by way of the secular work of conceptual interweaving."

38. Jævnfør Jacques Derridas kunstterm différance, der netop er et 'akustisk bedrag', men med en tilsvarende destabiliserende virkning på en orden, der bygger på tegn, repræsentation, lighed og analogi. Différance udgør derved en strukturel parallel til den her foreslåede dekonstruktive udlægning af homoousien, cf. Nancy (2008), 151. Hos Luhmann finder man en metodisk og teoretisk anstrengelse for at give denne dekonstruktive forskelshermeneutik en skarpere teoretisk formulering. 39. Luther Handbuch, red. Albrecht Beutel (Tübingen: Mohr Siebeck 2005), 365. Indholdet af den indre samtale melem Faderen og Sønnen fremgår af Luthersal- 
Således er treenighedsteologiens tankefigur attraktiv for Hegel som en kritik af rationalismens og deismens naturalistiske begreber om magt, suverænitet og selvopretholdelse. Disse begreber introduceres som totaltydninger i antropologi, teologi og politik. K.E Løgstrups religionsfilosofiske begreb om "Gud som magten til at være til i alt hvad der er til” er skåret over samme læst. ${ }^{40}$ Her bliver gudsbegrebet tænkt ud fra en participationsmetafysisk korrespondenslogik, hvor analogi og repræsentation muliggør bevægelsen fra konkrete fænomenologiske erfaringer og tydninger til den religiøse totaltydning. Heroverfor repræsenterer homoousien en selvreferentiel tilbagetrækning fra repræsentationens "naturlige" teologi. Hos Luther er alle teologiske begrebsdannelser "tågede", fordi de netop ikke blot afspejler, men selv frembringer en væren, og denne væren er kommunikativt bestemt som relationer og bevægelser i en radikal immanens. ${ }^{41}$

På linje hermed gentænkes treenigheden hos nutidige navne som Eberhard Jüngel som en rekapitulation af Guds historie med udgangspunkt i Kristusbegivenheden. Inkarnationen ombestemmer væren som en tilblivelse, der potentialiserer Gud. Tilblivelsen sætter et før og efter åbenbaringen og introducerer således en tidslig spænding i begrebet. Den temporale spænding er indeholdt i den eskatologiske forskydning af vulgærmetafysiske prædikater som uforanderlighed til en væren eller vorden, der fuldbyrdes i en kommen. Dermed vil Jüngel lægge grunden til en narrativ udfoldelse af bekendelsens gudsbegreb. Imidlertid kan den narrative formidling og den bestandige betoning af "tilblivelse" og "kommen" som guddommelige bevægelser og prædikater have brug for et korrektiv fra den uforanderlighed, som er indeholdt i Luthers insisteren på retfærdiggørelsens passive retfærdighed. Denne radikale passivitet kunne tænkes også at være homoousiens indre bevægelse og relation, som da snarere evokerer leg og snak. Den korsteologiske u/foranderlighed, som Jüngel vil potentialisere med sin treenighedstænkning, fører til en opvurdering af mulighed og tilblivelse frem for virkelighed og væren. I Phillipp Stoellgers kritiske reception af Jüngel, Gerhard Ebeling og Eilert Herms evokeringer af tilblivelse og mulighe, fremdrages Luthers drastiske og for moderne protestanter "irriterende" accentuering af, at mennesket over for Gud er apatisk og umusikalsk. ${ }^{42}$ Hermed fastholdes retfærdiggørelsens an-

men, $N u$ fryde sig hver kristen mand, der fremstiller samtalen (trialogen) mellem Faderen og Sønnen og mellem Sønnen og det fortabte menneske, og med Ånden som tilhører og hermeneutiker.

40. K.E. Løgstrup, Skabelse og tilintetgørelse (København: Gyldendal 1978), 58.

41. Martin Luther, "Disp. de divinitate et humanitate Christi”, WA 39 II, 104.

42. Phillipp Stoellger, Passivität aus Passion. Zur Problemgeschichte einer „categoria non grata" (Tübingen: Mohr Siebeck 2010), 249. 
tropologiske og teologiske betydning imod gerningsretfærdigheden, men vel at mærke uden at den retfærdiggjorte eller Gud selv udlægges i en tilblivelses- og muligheds-ontologi (Stoellger 2010, 1, 254-256, 261-266, 273-265). Retfærdiggørelsens modalitet er ifølge Stoellger "umulighed", alene fordi synden som oprør forudsætter, at mennesket er mere end passivt (Stoellger 2010 368-369). Med Luthers formel "iustificari mere passive" fastholdes netop umuligheden som en tværgående teologisk passivitet, som han udfolder med stødende og groteske kropsmetaforer (Stoellger 2010, 236-238), der modsætter sig hermeneutisk og ontologisk integration og progression. Luthers passivitetsmetaforik markerer systemgrænsen mellem sprogets og kroppens sfærer. Kristus var også Kristus, når han sov eller forrettede sin nødtørft. Således er de kristne ikke i mindre grad kristne, når de sover, er apatiske eller umusikalske. I Jüngels og nyere treenighedsteologiske udkast risikerer potentialiseringen af de teologiske figurer at afsvække retfærdiggørelsens eksklusivitet og fremmedhed. Menneskets virkelighed tænkes skolastisk og pædagogisk som et stof, der skal omformes i en helliggørende dannelsesproces. Besværgelsen af "tilblivelse" og "mulighed" forpasser korsets dårskab, der unddrager sig integrationen i forståelsen, men som i Stoellgers læsning åbner for andre krops- og mediefilosofiske perspektiver i J.-L. Nancys haptiske ontologi ${ }^{43}$ (Stoellger 2010 256-261).

Hvad der efter almindelig målestok gælder som kriterium for religionens succes, vendes i denne optik til spørgsmålet, som Tina Folke Drigsdahl stiller, "om kristendommen - som religion - er afviklet? Eller om den lever i bedste velgående - som religion? Og dermed hvis man vender sig til Nancy - som alt, hvad kristendom ikke er." 44

Fra de mediefilosofiske perspektiver, som har været anlagt i det foregående, kan treenighedsteologien anskues som en ny forståelse af sprogligheden som samtale og som en korrektur til den narrative udfoldelse. Mens sproget i den græske metafysik tænkes ud fra sætningen og talen, da implicerer treenighedsteologien, at sproget i stedet forstås ud fra samtalen og intersubjektiviteten. Personen og kroppen er ifølge disse konstitueret i en interpersonal proces, hvor "ordet bliver krop", og "kroppen bliver ord". Identiteten mellem substans og subjekt, legeme og sjæl foreligger således ikke som en umiddelbar selvbevidsthed, men fremkaldes af en tiltale, eksempelvis af samvittighedens stemme, der vidner om sproglighedens grundlæggende betydning. Den guddommelige tiltale kan ikke være ensidig, men består i en invitation til gensidighed, som fremgår af et vers i

43. J.-L. Nancy, Corpus (New York: Fordham University Press 2008).

44. Folke Drigsdahl, Præsentation af ph.d.-projektet Det helliges dekonstruktion. Ph.d.-dag ved Det Teologiske Fakultet 3. juni 2016. 
Luthersalmen $N u$ fryde sig hver kristenmand: "nu er jeg din og du er min". Udvekslingen i Gud-mennesket udgør forsoningens "underfulde bytte". Gud og menneske tænkes således ud fra sprogligheden som den samtale, vi selv er, og som grækerne delte med oldkirkens bekendelser. "Es ist da etwas in die Mitte niedergelegt, wie die Griechen sagen, an dem die Gesprächspartner teilhaben und worüber sie sich miteinander austauschen." ${ }^{45}$

Med sin udlægning af treenigheden som samtale har Luther således netop ifølge Joachim Ringleben inspireret den moderne sprogfilosofis grundlægger Wilhelm von Humboldt og Johann Gottlieb Fichte. ${ }^{46}$ Af salmen Nu fryde sig hver kristen mand fremgår det, hvad denne samtale drejer sig om, og hvordan Guds bevagelighed har at gøre med, at han afficeres, når det hedder, "da iamert Gott in Ewigkeit." ${ }^{77}$ Den treenige bevægelse udspiller sig som dialog mellem Faderen og Sønnen

Han talte til sin kære $\oint ø n:$

$\mathrm{Nu}$ vil jeg mig forbarme;

drag ud, mit hjertes krone skøn,

vær frelser for den arme;

gå, hjælp ham ud af syndens nød,

og dræb for ham den bitre død,

og lad med dig ham leve!

Forsoningens underfulde bytte fremgår af den afsluttende strofe: "Nu siger han: Kom hid til mig,/ tag evigt liv til gave!/Jeg led den bitre død for dig,/at du den arv skal have [...]. Luthers fortællende og dialogiske sammenfatning af treenighedsteologien har således overdraget den indre samtale i Gud til den samtale, vi selv er, og som er den midte, "som grækerne sagde", hvori noget, en sprogskat, der er overdraget og nedlagt iblandt os, inviterer til at blive taget op og udlagt (Gadamer 1972, 384). De moderne mediefilosofier handler om denne midte, som her har været taget op som ledetråd for en teologisk udlægning af spillet mellem kroppen, sproget og homooousien i den nikænske bekendelse.

45. Gadamer (1972), 384. For en udlægning heraf, se Jonas Holst Sørensen, "At tænke ud fra og omkring sprogets midte - en afsøgning af sprogets grænselandskab i Hans-Georg Gadamers tænkning”, Slagmark 40 (2004), 119-133.

46. Se Joachim Ringleben, "Trinität und Ich-Du-Verhältnis. Luther im Horizont des Sprachdenkens Humboldts gelesen" i samme, Arbeit am Gottesbegriff II (Tübingen: Mohr Siebeck 2005), 329-330.

47. Se Oswald Bayer, Martin Luthers Theologie. Eine Vergegenwärtigung (Tübingen Mohr Siebeck 2007), 193-201. 